\title{
AUDIT INTELLIGENCE AND AUDIT SURVIVAL: AN EMPIRICAL RESEARCH OF TAX AUDITORS (TAs) IN THAILAND
}

\author{
Sudarat Pongsatitpat, Mahasarakham Business School, Mahasarakham University, Thailand \\ Phapruke Ussahawanitchakit, Mahasarakham Business School, Mahasarakham University, Thailand \\ Kesinee Muenthaisong, Mahasarakham Business School, Mahasarakham University, Thailand
}

dx.doi.org/10.18374/JIBE-13-3.14

\begin{abstract}
This study investigates the effects of audit intelligence, audit value increase, audit report quality and financial information usefulness on audit survival of TAs in Thailand. Long-term audit vision, audit morality mindset, audit learning competency, regulatory force and stakeholder pressure become the antecedents of audit intelligence by using valuable audit experience as the moderator. In this study, 209 TAs in Thailand are the sample. The results indicate that audit intelligence influences audit value increase, audit report quality and financial information usefulness of TAs in Thailand. The results also present that long-term audit vision, audit morality mindset, audit learning competency, regulatory force and stakeholder pressure are the antecedents of that audit intelligence. Furthermore, audit value increase and financial information usefulness have a positive influence on audit survival. Finally, the advantages of audit intelligence will reach to long-term audit vision, audit morality mindset, audit learning competency, regulatory force and stakeholder pressure to support the auditor's work and enhance audit survival.

Keywords: Audit Intelligence, Audit Survival, Internal Control Evaluation, Operational Risk Assessment, Best Audit Practice Focus, Audit Planning Orientation, Audit Review Awareness, Audit Information Integration Concern, Long-term Audit Vision, Audit Morality Mindset, Audit Learning Competency, Regulatory Force, Stakeholder Pressure, Valuable Audit Experience
\end{abstract}

